\title{
Cerebral oxygenation and circulatory parameters during pressure-controlled vs volume-targeted mechanical ventilation in extremely preterm infants
}

\author{
Michalina Bugiera, ${ }^{1, D-D, F}$, Tomasz Szczapa ${ }^{1, A, D-F}$, Anna Sowińska ${ }^{2, C, F}$, \\ Charles Christoph Roehr ${ }^{3, \mathrm{E}, \mathrm{F}}$, Marta Szymankiewicz-Bręborowicz ${ }^{1, \mathrm{~A}, \mathrm{E}, \mathrm{F}}$ \\ 1 Department of Neonatology, Poznan University of Medical Sciences, Poland \\ ${ }^{2}$ Department of Computer Science and Statistics, Poznan University of Medical Sciences, Poland \\ ${ }^{3}$ Newborn Services, John Radcliffe Hospital, Oxford University Hospitals NHS Foundation Trust, United Kingdom \\ A - research concept and design; $B$ - collection and/or assembly of data; $C$ - data analysis and interpretation; \\ $D$ - writing the article; $E$ - critical revision of the article; $F$ - final approval of the article
}

Address for correspondence

Michalina Bugiera

E-mail: michalina.bugiera@gmail.com

Funding sources

None declared

Conflict of interest

None declared

Received on August 14, 2020

Reviewed on September 10, 2020

Accepted on 0ctober 7, 2020

Cite as

Bugiera M, Szczapa T, Sowińska A, Roehr CC, SzymankiewiczBręborowicz M. Cerebral oxygenation and circulatory parameters during pressure-controlled vs volume-targeted mechanical ventilation in extremely preterm infants. Adv Clin Exp Med. 2020;29(11):1325-1329.

doi:10.17219/acem/128198

DOI

10.17219/acem/128198

Copyright

Copyright by Author(s)

This is an article distributed under the terms of the

Creative Commons Attribution 3.0 Unported (CC BY 3.0)

(https://creativecommons.org/licenses/by/3.0/)

\begin{abstract}
Background. Respiratory distress syndrome (RDS) is the most common cause of respiratory failure of infants born prematurely with very low birth weight (VLBW). Essential elements of RDS management include ventilatory support and endotracheal administration of a surfactant.
\end{abstract}

Objectives. To assess the effect of volume-targeted compared to pressure-controlled mechanical ventilation (MV) on circulatory parameters and cerebral oxygenation $\mathrm{St}_{2}$ in extremely preterm infants.

Material and methods. This prospective, cross-over trial enrolled neonates born before 28 weeks of gestation. The patients were ventilated for $3 \mathrm{~h}$ in pressure-controlled assist-control (PC-AC) mode, followed by $3 \mathrm{~h}$ of volume-guarantee assist-control ventilation (VG-AC). Pulse oximetry (saturation ( $\mathrm{SpO}_{2}$ ) and heart rate (HR)), near-infrared spectroscopy (NIRS), $\mathrm{StO}_{2}$, and electrical cardiometry (EC) were used in monitoring of the patients.

Results. Twenty preterm infants with a mean gestational age of 26 weeks were studied. The patients' mean postnatal age was 7.7 days. The $\mathrm{SpO}_{2}$ values and HR were comparable during PC-AC and VG-AC. The mean values of peak inspiratory pressure (PIP), mean airway pressure (MAP) and expiratory tidal volume $\left(V T_{E}\right)$ were lower, while the respiratory rate (RR) was higher during PC-VG. There were no significant differences in the mean values of $\mathrm{StO}_{2}$, but based on a comparison of the standard deviations (SD) the $\mathrm{StO}_{2}$ variability was significantly lower during VG-AC. The circulatory parameters were comparable.

Conclusions. The $\mathrm{StO}_{2}$ is more stable during VG than $\mathrm{PC}$ ventilation. These findings support the use of VG mode in premature infants.

Key words: respiratory distress syndrome, volume-targeted ventilation, preterm infant, cerebral oxygenation, electrical cardiometry 


\section{Introduction}

Respiratory distress syndrome (RDS) is the most common cause of respiratory failure in infants born prematurely with a very low birth weight (VLBW). ${ }^{1}$ Its course may also influence other important complications of prematurity, such as intraventricular hemorrhage (IVH) or periventricular leukomalacia. ${ }^{2}$ Essential elements of RDS management include ventilatory support and endotracheal administration of a surfactant. ${ }^{1}$ The aim of mechanical ventilation (MV) is to ensure adequate gas exchange while avoiding lung injury. ${ }^{3}$ Neonatal MV can be provided using pressure-controlled (PC) or volume-targeted modes (VTV) such as volumeguarantee (VG), pressure-regulated volume control (PRVC) or volume-controlled ventilation (VCV). Historically, PC ventilation that directly controls inspiratory pressure used to be the standard mode for preterm infants until technology advanced enough to allow accurate delivery of small expiratory tidal volumes $\left(\mathrm{VT}_{\mathrm{E}}\right)$ using VTV. A meta-analysis conducted in 2017 presented the advantages of VTV over PC ventilation in the treatment of acute respiratory failure of newborns. Its use is associated with a reduced risk of death or bronchopulmonary dysplasia (BPD) and a reduction in the occurrence of pneumothorax, IVH stage III or IV, and periventricular leukomalacia. ${ }^{4}$ According to the European Consensus Guidelines on the Management of RDS 2019, VTV is the preferred mode of ventilation because it enables clinicians to ventilate with less variable $\mathrm{VT}_{\mathrm{E}}$ and to lower the pressure in real time as lung compliance improves. ${ }^{1}$ Despite the reported benefits and recommendations, VTV is not used routinely in every neonatal intensive care unit (NICU). One recent study conducted in Italy reported that VTV was chosen during the acute phase of RDS in only $27 \%$ of 113 tertiary NICUs, while in $45 \%$ of them this mode was only set during the weaning phase. ${ }^{5}$ The knowledge of the physiological effects of VTV is incomplete; therefore, the aim of this study was to assess the effects of VG ventilation on circulation and cerebral oxygenation $\left(\mathrm{StO}_{2}\right)$ in extremely premature infants.

\section{Material and methods}

This prospective crossover study was conducted at the Department of Neonatology of Poznan University of Medical Sciences, Poland, after approval from the Bioethical Committee (decision No. 388/16). Premature infants born before 28 weeks of gestation were enrolled in the study with written parental consent when the following criteria were met: 1) respiratory failure in the course of RDS requiring $M V$, 2) stable condition with $\mathrm{pH}>7.2$ and $\mathrm{pCO}_{2}<60 \mathrm{~mm} \mathrm{Hg}$ in the blood gas analysis, and 3) no identified genetic syndromes or serious congenital malformations.

The study was carried out after initial stabilization when no other interventions that could influence the ventilatory status had been performed (e.g., surfactant administration, rescue high-frequency ventilation, pneumothorax, or surgical treatment). In each newborn, pressure controlled assist-control (PC-AC) ventilation was carried out for $3 \mathrm{~h}$ followed by AC VG ventilation for $3 \mathrm{~h}$ using a Dräger Babylog VN500 ventilator (Drägerwerk AG, Lübeck, Germany). The $\mathrm{VT}_{\mathrm{E}}$ was set in the range of $4-6 \mathrm{~mL} / \mathrm{kg}$, aiming for the values observed during $\mathrm{PC}$ ventilation. The $\mathrm{FiO}_{2}$ was titrated manually to keep the peripheral oxygen saturation $\left(\mathrm{SpO}_{2}\right)$ in the range of $90-95 \%$.

During the study, $\mathrm{StO}_{2}$ was measured using a near-infrared spectroscopy (NIRS) monitor (NONIN SenSmart X-100; Nonin Medical Inc., Plymouth, USA) with the pediatric sensor (EQUANOX Advance; Nonin Medical Inc.) placed on the patient's forehead. A pulse oximetry module integrated with the NIRS oximeter was used simultaneously to assess heart rate (HR) and $\mathrm{SpO}_{2}$ which allowed the fractional oxygen extraction to be calculated $\left(\mathrm{FOE}=\left(\mathrm{SpO}_{2}-\mathrm{StO}_{2}\right) / \mathrm{SpO}_{2}\right){ }^{6}$

Continuous, non-invasive monitoring of hemodynamic parameters, such as stroke volume (SV), cardiac output (CO), stroke index (SI), cardiac index (CI), stroke volume variation (SVV), and index of contractility (ICON), was performed using electrical cardiometry (EC) with 4 electrocardiography (ECG) electrodes placed on the left side of the infant's body (ICON; Osypka Medical, La Jolla, USA).

The Shapiro-Wilk test, Student's t-test, and the Wilcoxon test were used in the statistical analysis (STATISTICA v. 12; StatSoft, Inc., Tulsa, USA) with p-values $<0.05$ considered significant.

\section{Results}

Twenty-five neonates were included in the study. Four patients had to be excluded due to the poor quality of the records and 1 due to prenatal exposure to methamphetamine (confirmed in the urine test). All patients received surfactant replacement therapy after birth. Data from 20 newborns was included in the final analysis. The patients' demographic and clinical parameters are presented in Tables 1 and 2.

The expiratory minute volumes $\left(\mathrm{MV}_{\mathrm{E}}\right)$ were comparable during PC and VG ventilation. With VG ventilation, mean airway pressure (MAP) and peak inspiratory pressure (PIP) were significantly reduced, whereas the standard deviation (SD) of MAP and PIP were higher in VG mode. A lower $\mathrm{VT}_{\mathrm{E}}$ was delivered at higher respiratory rates (RRs) during VG ventilation (Table 3).

No significant differences in mean $\mathrm{StO}_{2}$ values were found between PC and VG ventilation (Table 4), though the $\mathrm{StO}_{2} \mathrm{SD}$ was significantly higher during the PC mode, suggesting higher variability (Fig. 1).

The mean values and SD of hemodynamic parameters were not significantly different during PC and VG ventilation (Table 5). Mean values of HR were similar during both modes of ventilation, but there was a trend for lower variability of this parameter during the VG ventilation. 
Table 1. Characteristics of the study group

\begin{tabular}{|c|c|c|c|c|c|}
\hline Parameter & Mean & Median & Standard deviation & Minimum & Maximum \\
\hline Gestational age [weeks] & $254 / 7$ & $253 / 7$ & 1 & $244 / 7$ & $276 / 7$ \\
\hline Body weight [g] & 848 & 803 & 138 & 620 & 1070 \\
\hline Postnatal age [days] & 7.7 & 5.5 & 5.3 & 2 & 21 \\
\hline Surfactant doses & 1.6 & 1 & 0.7 & 1 & 3 \\
\hline Starting $\mathrm{FiO}_{2}$ & 0.27 & 0.24 & 0.08 & 0.21 & 0.5 \\
\hline
\end{tabular}

Table 2. Selected perinatal data and complications in the study group

\begin{tabular}{|l|c|}
\multicolumn{1}{|c|}{ Parameter } & Value \\
\hline Age of the mother [years] [mean; range] & $30 ; 19-41$ \\
\hline Pregnancy-induced hypertension ( $n, \%)$ & $1 ; 5 \%$ \\
\hline Prenatal steroids (n, \%) & $16 ; 80 \%$ \\
\hline Cesarean section ( $n$, \%) & $13 ; 65 \%$ \\
\hline Premature rapture of membranes (n, \%) & $8 ; 40 \%$ \\
\hline Early onset sepsis (n, \%) & $2 ; 10 \%$ \\
\hline Pneumothorax (n, \%) & $1 ; 5 \%$ \\
\hline Pulmonary interstitial emphysema (n, \%) & $3 ; 15 \%$ \\
\hline Pulmonary hypertension (n, \%) & $1 ; 5 \%$ \\
\hline Bronchopulmonary dysplasia (n, \%) & $19 ; 95 \%$ \\
\hline Patent ductus arteriosus requiring treatment (n, \%) & $11 ; 55 \%$ \\
\hline Severe intraventricular hemorrhage (grades III-IV) (n, \%) & $3 ; 15 \%$ \\
\hline Retinopathy of prematurity requiring treatment (n, \%) & $9 ; 45 \%$ \\
\hline Death before discharge (n, \%) & $2 ; 10 \%$ \\
\hline
\end{tabular}

\section{Discussion}

The purpose of the study was to investigate the effect of $\mathrm{VG}$ ventilation on $\mathrm{StO}_{2}$ and cardiac function in extremely premature infants. We found that while cardiac parameters were similar with both modes of ventilation, $\mathrm{StO}_{2}$ was more stable during VTV.

The challenging aspects of MV in premature infants include the high RR, the low and rapidly changing lung compliance, and the very short inspiratory time and small $\mathrm{VT}_{\mathrm{E}}$ in combination with a relatively large gas leakage and dead space volume. ${ }^{7}$ The prevailing influence of volutrauma over barotrauma on the risk of ventilator-induced lung injury (VILI) in neonates confirmed in animal models and in clinical trials make VTV the preferred "lung-protective" strategy of MV. ${ }^{3}$

The results confirm the beneficial respiratory effects of VTV. As in previous studies, VG ventilation provided

Table 3. Ventilation parameters during PC and VG ventilation

\begin{tabular}{|c|c|c|c|c|}
\hline \multicolumn{2}{|c|}{ Parameter } & PC & VG & p-value \\
\hline \multirow{2}{*}{$\mathrm{RR}[1 / \mathrm{min}]$} & mean & 49 & 53 & $<0.02$ \\
\hline & SD & 7.6 & 10.7 & ns \\
\hline \multirow{2}{*}{ PIP [mbar] } & mean & 18.3 & 16.7 & $<0.0001$ \\
\hline & SD & 2.9 & 3.2 & $<0.00001$ \\
\hline \multirow{2}{*}{ MAP [mbar] } & mean & 8.7 & 8.4 & $<0.01$ \\
\hline & SD & 1.1 & 1.3 & $<0.01$ \\
\hline \multirow{2}{*}{$M V_{E}[\mathrm{~L} / \mathrm{min}]$} & mean & 0.25 & 0.25 & ns \\
\hline & SD & 0.07 & 0.08 & $<0.001$ \\
\hline \multirow{2}{*}{$V T_{E}[\mathrm{~mL} / \mathrm{kg}]$} & mean & 6.1 & 5.8 & $<0.04$ \\
\hline & SD & 1.2 & 1.1 & $<0.0001$ \\
\hline
\end{tabular}

$R R$ - respiratory rate; PIP - peak inspiratory pressure; $M A P$ - mean airway pressure; $M V_{E}$ - expiratory minute volume; $V T_{E}$ - expiratory tidal volume; SD - standard deviation; ns - not significant.

Table 4. Cerebral oxygenation, peripheral oxygen saturation and fractional oxygen extraction during PC and VG ventilation

\begin{tabular}{|c|c|c|c|c|}
\hline \multicolumn{2}{|c|}{ Parameter } & PC & VG & $p$-value \\
\hline \multirow{2}{*}{$\mathrm{StO}_{2}(\%)$} & mean & 80.7 & 80.4 & ns \\
\hline & SD & 2.7 & 2.2 & $p<0.01$ \\
\hline \multirow{2}{*}{$\mathrm{SpO}_{2}(\%)$} & mean & 93.7 & 93.3 & ns \\
\hline & SD & 2.8 & 2.6 & ns \\
\hline \multirow{2}{*}{ FOE } & mean & 0.14 & 0.14 & $\mathrm{~ns}$ \\
\hline & SD & 0.04 & 0.04 & ns \\
\hline
\end{tabular}

$\mathrm{SD}$ - standard deviation; $\mathrm{ns}$ - not significant; $\mathrm{StO}_{2}$ - cerebral oxygenation; $\mathrm{SpO}_{2}$ - peripheral oxygen saturation; FOE - fractional oxygen extraction. 
Table 5. Hemodynamic parameters during PC and VG ventilation

\begin{tabular}{|c|c|c|c|c|}
\hline \multicolumn{2}{|c|}{ Parameter } & PC & VG & $p$-value \\
\hline \multirow{2}{*}{ Heart rate $[1 / \mathrm{min}]$} & mean & 140 & 145 & ns \\
\hline & SD & 5.1 & 4.6 & ns \\
\hline \multirow{2}{*}{ Stroke volume $[\mathrm{mL}]$} & mean & 1.7 & 1.6 & ns \\
\hline & SD & 0.14 & 0.13 & ns \\
\hline \multirow{2}{*}{ Cardiac output [L/min] } & mean & 0.24 & 0.23 & ns \\
\hline & SD & 0.06 & 0.06 & ns \\
\hline \multirow{2}{*}{ Index of contractility } & mean & 115 & 115 & ns \\
\hline & SD & 23 & 18 & ns \\
\hline \multirow{2}{*}{ Stroke index $\left[\mathrm{mL} / \mathrm{m}^{2}\right]$} & mean & 19 & 19.5 & ns \\
\hline & SD & 1.6 & 1.7 & ns \\
\hline \multirow{2}{*}{ Cardiac index $\left[\mathrm{L} / \mathrm{min} / \mathrm{m}^{2}\right]$} & mean & 2.8 & 2.9 & ns \\
\hline & SD & 0.4 & 0.4 & ns \\
\hline \multirow{2}{*}{ Stroke volume variation (\%) } & mean & 14 & 13 & ns \\
\hline & SD & 3.8 & 5.4 & ns \\
\hline
\end{tabular}

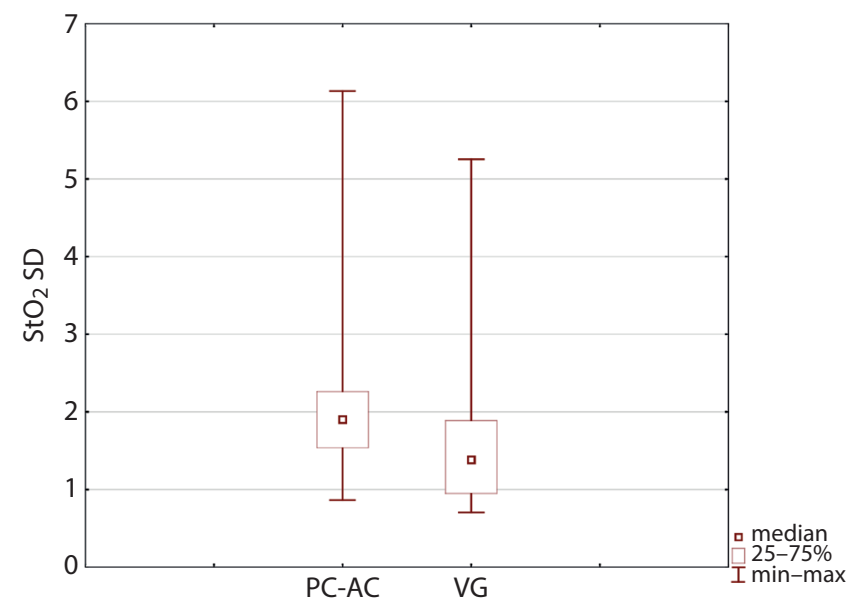

Fig. 1. Standard deviation of $\mathrm{StO}_{2}$ during $P C$ and VG ventilation

patients with more stable ventilation and lower airway pressures (PIP and MAP). ${ }^{8}$ Lower $\mathrm{V}_{\mathrm{T}}$ values during VG ventilation with an $M V_{E}$ similar to the $P C$ ventilation period may explain the increase in $R R$. The lower variability of $\mathrm{MV}_{\mathrm{E}}$ during VG mode suggests a more balanced ventilation.

Continuous measurement of $\mathrm{StO}_{2}$ has been used to identify newborns with a higher risk of brain damage. ${ }^{9} \mathrm{The}^{\mathrm{StO}}{ }_{2}$ levels that are either too high or too low have been identified as risk factors for cerebral injury. ${ }^{10}$ Our results have shown no statistically significant differences between the mean values of $\mathrm{StO}_{2}$ and $\mathrm{FOE}$ during $\mathrm{PC}$ when compared to VG ventilation, which is similar to the findings of a small pilot study that compared PC synchronized intermittent ventilation (SIMV) with VG SIMV. ${ }^{11}$ In both groups, the mean $\mathrm{StO}_{2}$ was about $80 \%$, which is in the upper range of values considered to be normal in the neonate. ${ }^{12}$ However, we found that the $\mathrm{StO}_{2}$ variability was significantly lower during VG ventilation. The more stable
$\mathrm{StO}_{2}$ during the VTV mode could be attributed to more stable ventilation, as $\mathrm{CO}_{2}$ is an important regulator of cerebral blood flow. ${ }^{13,14}$ The association between $\mathrm{CO}_{2}$ fluctuations and $\mathrm{StO}_{2}$ is well-known in preterm neonates. An acute increase in $\mathrm{CO}_{2}$ may result in increased $\mathrm{StO}_{2}$ with decreased electrical activity, while hypocapnia has an opposite effect and increases FOE. ${ }^{15,16}$ The significantly higher variability of $\mathrm{StO}_{2}$ was previously reported in preterm infants with RDS when compared to without RDS. ${ }^{2}$ Hence, VG ventilation in this group of patients would be expected to provide an important "brain-protective" effect by better stabilizing the cerebral brain fluid. Data from clinical trials and meta-analyses confirm this assumption, showing a significantly lower risk of IVH in patients ventilated using VTV modes. ${ }^{17}$

Mechanical ventilation with VG is thought to facilitate a more constant ventilation-to-perfusion ratio, which should translate into improved clinical stability, including $\mathrm{StO}_{2}$ as well as hemodynamic parameters. The stable volume of breath administered with each inspiration causes less distension of the lungs, resulting in more constant venous return to the left atrium. To our knowledge, this is the first study that compared hemodynamic parameters between PC and VG modes of MV by the means of EC. It is a non-invasive method that evaluates cardiac function based on modified thoracic electrical bioimpedance. The measurement is based on the relationship between the change in tissue resistance and blood flow through the large arteries. ${ }^{18}$ This method employs a very low current of 2-4 mA and a high frequency of $20-100 \mathrm{~Hz}$, which makes it a completely painless and safe method. Numerous comparisons between EC and echocardiography have shown a close correlation of the results, even in very premature newborns. ${ }^{19,20}$ The selected hemodynamic parameters were stable throughout the study and no statistically significant differences were found between PC and VG MV. 
However, there was a trend for lower variability of HR during VG ventilation. This seems to indicate that VG mode does not have equally significant effects on ventilatory and circulatory status when PC ventilation is carefully monitored and adjusted.

These results should be interpreted with caution due to the limitations of the study, which include the relatively small size of the study group, the limited observation time and the lack of transcutaneous blood gas monitoring, which could provide additional information on the potential link between $\mathrm{CO}_{2}$ and $\mathrm{StO}_{2}$ variability.

Our results confirm the beneficial respiratory and cerebral effects of VTV in extremely premature infants. The findings add to the existing evidence supporting the use of VTV modes of ventilation in a neonatal intensive care setting.

\section{ORCID iDs}

Michalina Bugiera (10 https://orcid.org/0000-0003-1787-1681 Tomasz Szczapa (1) https://orcid.org/0000-0002-5214-2719 Anna Sowińska (1) https://orcid.org/0000-0001-5319-5057 Charles Christoph Roehr (10 https://orcid.org/0000-0001-7965-4637 Marta Szymankiewicz-Bręborowicz

(1) https://orcid.org/0000-0002-7389-0708

\section{References}

1. Sweet DG, Carnielli V, Greisen,G, et al. European Consensus Guidelines on the Management of Respiratory Distress Syndrome - 2019 update. Neonatology. 2019;115(4):432-450.

2. Lemmers PM, Toet $M$, van Schelven LJ, van Bel F. Cerebral oxygenation and cerebral oxygen extraction in the preterm infant: The impact of respiratory distress syndrome. Exp Brain Res. 2006;173(3):458-467.

3. Reiterer F, Schaberger B, Freidl T, Schmölzer G, Pichler G, Urlesberger B. Lung-protective ventilatory strategies in intubated preterm neonates. Paediatr Respir Rev. 2017;23:89-96.

4. Klingenberg C, Wheeler KI, McCallion N, et al. Volume-targeted versus pressure-limited ventilation in neonates. Cochrane Database Syst Rev. 2017;10(10):CD003666.

5. Petrillo F, Gizzi C, Maffei G, et al; Neonatal Pneumology Study Group Italian Society of Neonatology. Neonatal respiratory support strategies for the management of extremely low gestational age infants: An Italian survey. Ital J Pediatr. 2019;45(1):44.
6. Pellicer A, Bravo Mdel C. Near-infrared spectroscopy: A methodologyfocused review. Semin Fetal Neonatal Med. 2011;16(1):42-49.

7. Roumiantsev $S$. Invasive mechanical ventilation in premature infants: Where do we stand today? J Pulmon Resp Med. 2013;2013:S13.

8. Duman N, Tuzun F, Sutcuoglu S, Yesilirmak CD, Kumral A, Ozkan H. Impact of volume guarantee on synchronized ventilation in preterm infants: A randomized controlled trial. Intensive Care Med. 2012;38(8): 1358-1364.

9. Hyttel-Sorensen S, Greisen G, Als-Nielsen B, Gluud C. Cerebral nearinfrared spectroscopy monitoring for prevention of brain injury in very preterm infants. Cochrane Database Sys Rev. 2017;9(9):CD011506.

10. Greisen $\mathrm{G}$, Leung $\mathrm{T}$, Wolf $\mathrm{M}$. Has the time come to use near-infrared spectroscopy as a routine clinical tool in preterm infants undergoing intensive care? Philos Trans A Math Phys Eng Sci. 2011;369(1955): $4440-4451$.

11. Dotta A, Crescenzi F, Campi F, et al. Cerebral haemodynamics and lung mechanics in preterm infants during synchronized intermittent mandatory ventilation (SIMV) and synchronized intermittent positive pressure ventilation (SIPPV), with and without volume guaranteed (VG). Pediatr Res. 2004;56(3):498.

12. McNeil S, Gatenby JC, McElroy S, Engelhardt B. Normal cerebral, renal and abdominal regional oxygen saturations using near-infrared spectroscopy in preterm infants. J Perinatol. 2011;31(1):51-57.

13. Greisen G. Autoregulation of cerebral blood flow in newborn babies. Early Hum Dev. 2005;81(5):423-428.

14. Noori S, Anderson M, Soleymani S, Seri I. Effect of carbon dioxide on cerebral blood flow velocity in preterm infants during postnatal transition. Acta Paediatr. 2014;103(8):e334-e339.

15. Dix LML, Weeke LC, de Vries LS, et al. Carbon dioxide fluctuations are associated with changes in cerebral oxygenation and electrical activity in infants born preterm. J Pediatr. 2017;187:66-72.e1.

16. Kissack CM, Garr R, Wardle SP, Weindling AM. Cerebral fractional oxygen extraction in very low birth weight infants is high when there is low left ventricular output and hypocarbia but is unaffected by hypotension. Pediatr Res. 2004;55(3);400-405.

17. van Kaam AH, Rimensberger PC. Lung-protective ventilation strategies in neonatology: What do we know - what do we need to know? Crit Care Med. 2007;35(3):925-931.

18. McGovern M, Miletin J. Cardiac output monitoring in preterm infants. Front Pediatr. 2018;6:84.

19. Song R, Rich W, Kim JH, Finer NN. The use of electrical cardiometry for continuous cardiac output monitoring in preterm neonates: A validation study. Am J Perinatol. 2014;31(12):1105-1110.

20. Grollmuss O, Gonzalez P. Non-invasive cardiac output measurement in low and very low birth weight infants: A method comparison. Front Peadiatr. 2014;2:16. 